\title{
PROCESSO DE TERAPIA TRANSFUSIONAL EM UNIDADE DE TERAPIA INTENSIVA NEONATAL: O CONHECIMENTO DO ENFERMEIRO
}

\author{
Estefânia de Oliveira Cherem ${ }^{1}$, Valdecyr Herdy Alves², Diego Pereira Rodrigues ${ }^{3}$, Paula Cristina de Oliveira \\ Pimenta ${ }^{4}$ Fernanda Dalabella Lisboa Souza ${ }^{5}$, Juliana Vidal Vieira Guerra ${ }^{6}$
}

${ }^{1}$ Mestre em Saúde Materno-Infantil. Enfermeira do Hospital Sofia Feldman. Belo Horizonte, Minas Gerais, Brasil. E-mail: thecherem@ yahoo.com.br

2 Doutor em Enfermagem. Professor do Departamento Materno-Infantil e Psiquiátrico da Escola de Enfermagem Aurora de Afonso Costa da Universidade Federal Fluminense (UFF). Rio de Janeiro, Rio de Janeiro, Brasil. E-mail: herdyalves@yahoo.com.br

${ }^{3}$ Doutorando do Programa de Pós-graduação em Enfemagem da UFF. Rio de Janeiro, Rio de Janeiro, Brasil. E-mail: diego.pereira. rodrigues@gmail.com

${ }^{4}$ Mestre em Saúde Materno-Infantil. Enfermeira do Hospital Sofia Feldman. Belo Horizonte, Minas Gerais, Brasil. E-mail: paulacopimenta@gmail.com

${ }^{5}$ Enfermeira do Hospital Sofia Feldman. Belo Horizonte, Minas Gerais, Brasil. E-mail: fedolabella@yahoo.com.br

${ }^{6}$ Mestre em Saúde Materno-Infantil. Nutricionista da Prefeitura Municipal de São João da Barra. Rio de Janeiro, Rio de Janeiro, Brasil. E-mail: julianavvguerra@yahoo.com.br

\section{RESUMO}

Objetivo: analisar o conhecimento do enfermeiro da Unidade de Terapia Intensiva Neonatal acerca do processo da terapia transfusional. Método: estudo descritivo, exploratório, qualitativo, realizado no segundo semestre de 2014 em dois hospitais da cidade de Belo Horizonte, no Estado de Minas Gerais(Brasil). Foram entrevistados 35 enfermeiros. Os dados foram submetidos à análise de conteúdo na modalidade temática.

Resultados: a categoria temática o processo pré-transfusional na atenção ao recém-nascido e sua interface para o cuidado obteve duas subcategorias: Contextualizando a prática na indicação transfusional e nos exames de compatibilidade sanguínea; e Os cuidados de enfermagem ao recém-nascido ante o procedimento transfusional. Com isso, os enfermeiros citaram a importância da conferência da bolsa de sangue, punção do acesso venoso periférico e a não administração de antibiótico no momento da infusão.

Conclusão: comprovou-se que os enfermeiros têm conhecimento acerca do processo pré-transfusional, embora alguns passos importantes no cuidado não tenham sido mencionados, mostrando a necessidade de melhor capacitação desses profissionais no cuidado vinculado à terapia transfusional.

DESCRITORES: Transfusão de sangue. Transfusão de componentes sanguíneos. Enfermagem neonatal. Cuidados de enfermagem. Unidades de terapia intensiva neonatal.

\section{THE TRANSFUSIONAL THERAPY PROCESS IN THE NEONATAL INTENSIVE THERAPY UNIT: THE NURSE'S KNOWLEDGE}

\section{ABSTRACT}

Objective: to analyze the knowledge of nurses from the Neonatal Intensive Care Unit regarding the transfusion therapy process.

Method: descriptive, exploratory, qualitative study carried out in the second half of 2014 in two hospitals in the city of Belo Horizonte, State of Minas Gerais (Brazil), 35 nurses were interviewed. The data were submitted to thematic content analysis.

Results: the thematic categories pre-transfusion process for newborns $\backslash$ and its connection to care obtained two subcategories: Contextualizing the practice in the indication for transfusion and in the blood compatibility exams; and Nursing care for the newborn before the transfusion procedure. Nurses cited the importance of blood bag verification, obtaining peripheral venous access, and avoiding the administration of antibiotics at the time of infusion.

Conclusion: it was verified that nurses are aware of the pre-transfusion process, although some important steps in the care process have not been mentioned, showing the need for improved training of these professionals in the care related to transfusion therapy.

DESCRIPTORS: Blood transfusion. Transfusion of blood components. Neonatal nursing. Nursing care. Neonatal intensive care units. 


\section{PROCESO DE TERAPIA TRANSFUSIONAL EN UNIDAD DE TERAPIA INTENSIVA NEONATAL: EL CONOCIMIENTO DEL ENFERMERO}

RESUMEN

Objetivo: analizar el conocimiento del enfermero de la Unidad de Terapia Intensiva Neonatal acerca del proceso de la terapia transfusional. Método: estudio descriptivo, exploratorio, cualitativo, realizado en el segundo semestre de 2014 en dos hospitales de la ciudad de Belo Horizonte, en el Estado de Minas Gerais (Brasil). Se entrevistaron a 35 enfermeros. Los datos fueron sometidos al análisis de contenido en la modalidad temática.

Resultados: el proceso pre-transfusional en la atención al recién nacido y su interfaz para el cuidado obtuvo dos subcategorías: Contextualizando la práctica en la indicación transfusional y en los exámenes de compatibilidad sanguínea; y los cuidados de enfermería al recién nacido ante el procedimiento transfusional. Con ello, los enfermeros citaron la importancia de la verificación de la bolsa de sangre, punción del acceso venoso periférico y la no administración de antibiótico en el momento de la infusión.

Conclusión: se comprobó que los enfermeros tienen conocimiento acerca del proceso pre-transfusional, aunque algunos pasos importantes en el cuidado no han sido mencionados, mostrando la necesidad de una mejor capacitación de estos profesionales en el cuidado vinculado a la terapia transfusional.

DESCRIPTORES: Transfusión sanguínea. Transfusión de componentes sanguíneos. Enfermería neonatal. Atención de enfermería. Unidades de cuidado intensiva neonatal.

\section{INTRODUÇÃO}

A terapêutica transfusional (TT) refere-se à transfusão de partes específicas do sangue das quais o paciente realmente necessita, opondo-se ao uso do sangue total. Trata-se de procedimento que visa beneficiar vários pacientes, bem como otimizar os estoques dos bancos de sangue. ${ }^{1}$

As competências e atribuições do enfermeiro em hemoterapia são regulamentadas pela Resolução n. 306, de 25 de abril de 2006, do Conselho Federal de Enfermagem (COFEN), que estabelece a sua responsabilidade pelo planejamento, execução, coordenação, supervisão e avaliação de procedimentos de hemoterapia em unidades de saúde, entre outros visando assim assegurar a qualidade do sangue e dos hemocomponentes/hemoderivados coletados e transfundidos. ${ }^{2-3}$

A hemotransfusão é de suma importância para a equipe médica e, sobretudo, para a de enfermagem, uma vez que cabe ao enfermeiro acompanhar todo o processo transfusional. ${ }^{4}$

A TT, mesmo com indicação precisa e administração correta, precisa respeitar todas as normas técnicas preconizadas, porque envolve risco sanitário. A segurança e a qualidade do sangue e dos hemocomponentes devem ser asseguradas durante todo o processo, desde a captação de doadores até a administração no paciente. Por isso, a importância de se cumprir com eficiência o ciclo hemoterápico, cujo processo inicia-se com a captação e seleção de doadores, seguindo-se as triagens sorológica e imunohematológica, processamento e fracionamento das unidades coletadas, dispensação, transfusão e avaliação pós-transfusional. ${ }^{2}$ Ressalta-se que existem duas formas de obtenção dos hemocomponentes, sendo a mais comum a coleta do sangue total. A segunda é a coleta por aférese, mais específica e de maior complexidade, devendo o enfermeiro, portanto, ter conhecimento acerca do processo transfusional. ${ }^{5}$

A transfusão de hemocomponentes e hemoderivados é uma tecnologia relevante na terapêutica moderna e quando utilizada de forma adequada pode salvar vidas e melhorar a saúde dos pacientes. ${ }^{6}$ Em várias situações clínicas, uma transfusão sanguínea pode representar a única maneira de salvar uma vida ou estabilizar o quadro do paciente, mas quando realizada inadequadamente, pode agravá-lo ou mesmo desencadear o óbito. Desse modo, constitui um processo complexo, que exige acompanhamento por parte dos profissionais, principalmente da equipe de enfermagem que presta cuidados diretos ao paciente. ${ }^{7}$

A segurança na administração do sangue depende de indivíduos realizando um trabalho completo e competente. Ter procedimentos padronizar e disponíveis para prover a equipe de instruções adequadas e consistentes de como proceder nos cuidados do paciente receptor de transfusão, certamente, contribui para aumentar a segurança transfusional. ${ }^{8}$

O enfermeiro exerce um papel fundamental na segurança transfusional, pois ele não apenas administra transfusões, mas detém o conhecimento das indicações e providencia a checagem de dados, elementos importantes na prevenção de erros, como também orienta os responsáveis legais dos pacientes sobre os benefícios e riscos da terapia transfusional, como a transmissão de doenças e reações adversas. ${ }^{9}$ Nesse sentido, necessita de capacitação constante, pois precisa estar preparado para assumir suas responsabilidades, atribuições e competências pro- 
fissionais. Deve-se romper com a dicotomia entre a prática e o conhecimento científico em hemoterapia, para que se diminuam os riscos à saúde. ${ }^{9}$ No entanto, muitos enfermeiros sentem-se despreparados para exercer suas atividades junto à pacientes que necessitam de hemotransfusão. ${ }^{10}$

Desse modo, julga-se relevante o estudo por enfocar a temática, principalmente no que diz respeito a esse procedimento na Unidade de Terapia Intensiva Neonatal (UTIN), visto que o público internado nesse setor necessita de cuidados especializados e contínuos para sua sobrevida e estabilidade na saúde neonatal. Portanto, uma equipe com níveis adequados de conhecimento é essencial para um sistema seguro, de modo a proporcionar maior segurança ao paciente, já que é necessário assegurar a qualidade do sangue durante todo o processo. ${ }^{5}$

Nesse contexto, os recém-nascidos (RNs) hospitalizados na UTIN constituem um grupo de pacientes que, proporcionalmente, mais consome hemocomponentes. A hemotransfusão em neonatologia tem uma abordagem diferente daquela do adulto, devido às seguintes características: maior sensibilidade ao frio; maior risco de anóxia tecidual; imaturidade metabólica e imunológica; fisiologia hematológica; peculiar e patologia própria do RN. .910 $^{9-10}$ Desse modo, o conhecimento por parte do enfermeiro torna-se essencial para promover esse cuidado especializado, assumindo um compromisso com a saúde, a qualidade de vida e o cuidado neonatal. ${ }^{11-12}$

Os erros cometidos durante a transfusão de sangue podem ser evitados se reforçados os sistemas e processos hospitalares relacionados a esse procedimento, bem como o preparo da equipe profissional envolvida. ${ }^{12}$ Embora seja impossível eliminar totalmente a possibilidade de erros humanos, reduzir as oportunidades para que ocorram pode ser um objetivo facilmente alcançável, assim promovendo melhor segurança para o paciente. ${ }^{11-12}$

Nesse sentido, o estudo pretendeu responder a seguinte indagação: como se apresenta o saber dos enfermeiros que atuam na UTIN em relação à prática pré-transfusional? Já que esses profissionais como responsáveis pela equipe de enfermagem, devem estar capacitados para atuar no processo da TT e fornecer orientações junto à equipe e à família do paciente, gerando segurança e confiança no processo de cuidado.

Sendo assim, pretende-se mostrar com este estudo o grau de conhecimento dos enfermeiros e da equipe de enfermagem no que diz respeito à etapa inicial do processo de transfusão sanguínea, bem como o nível de exposição do RN a riscos des- necessários por desconhecimento do assunto ou imperícia técnica durante o procedimento.

Diante do exposto, o estudo teve como objetivo analisar o conhecimento dos enfermeiros da UTIN acerca do processo da terapia transfusional.

\section{MÉTODO}

Pesquisa descritiva, exploratória, com abordagem qualitativa. Considerada apropriada ao objetivo do estudo, pois procura desvelar os dados subjetivos dos indivíduos a fim de contribuir com o conhecimento dos enfermeiros no processo transfusional na UTIN.

Os participantes do estudo foram 35 enfermeiros de duas UTINs na cidade de Belo Horizonte, Estado de Minas Gerais, a saber: Hospital Sofia Feldman e Hospital Odete Valadares, ambas de referência para cuidados especializados em neonatologia.

Foram estabelecidos os seguintes critérios de inclusão: ser enfermeiro especialista em neonatologia e atuar na assistência direta na unidade de saúde. Os critérios de exclusão levaram em conta ser enfermeiro com cargo gerencial e estar ausentes de suas atividades assistenciais por licença, férias ou auxílio-doença.

Aqueles que atenderam aos critérios de inclusão foram convidados a participar do estudo por meio da seleção aleatória simples, a partir do quadro de profissionais de saúde, em que foi feita a escolha dos enfermeiros a partir da numeração de matricula ímpar ao final do número. A partir do aceite dos participantes, foi-lhes esclarecido o tema da pesquisa e solicitada a assinatura do Termo de Consentimento Livre e Esclarecido (TCLE), condicionando a sua participação voluntária, assegurando-se-lhes o anonimato e o sigilo das informações com a utilização de um código alfanumérico (PS1... PS35), assim viabilizando a aplicação do instrumento de coleta de dados.

Em conformidade com a Resolução n. 466/ 2012 do Conselho Nacional de Saúde (CNS), o estudo foi aprovado pelo Comitê de Ética em Pesquisa (CEP) da Faculdade de Medicina do Hospital Universitário Antônio Pedro (HUAP) da Universidade Federal Fluminense (UFF), sob Protocolo n. 624.384/2014 e CAAE n. 25871814.1.0000.5243.

A coleta de dados foi realizada ao longo do segundo semestre de 2014, com a aplicação de entrevista semiestruturada, cujo roteiro continha perguntas abertas e fechadas referentes ao processo de hemotransfusão na UTIN. A coleta dos depoimentos dos participantes foi gravada em apa- 
relho digital, com a respectiva autorização prévia. Posteriormente, as entrevistas foram transcritas na íntegra pelo pesquisador com a finalidade de assegurar a fidedignidade das falas. As entrevistas foram realizadas pela própria pesquisadora e por uma enfermeira especialista em neonatologia, a qual foi treinada previamente. O tempo de duração das entrevistas foi em média de 30 minutos, podendo os entrevistados discorrerem com tranquilidade sobre o assunto.

Para analisar o material coletado nas entrevistas, optou-se pela análise de conteúdo, ${ }^{13}$ que é um método de busca de informação; logo, tem como objetivos a ultrapassagem da incerteza e o enriquecimento da leitura, obtidos quando o pesquisador observa as condições de produção do discurso, efetua inferências sobre as mensagens sistematizadas e orienta o contexto da produção. As seguintes operações são pertinentes ao método: 1) codificação: realizada a partir do recorte que diz respeito à escolha das unidades; da enumeração, que se refere às regras de contagem; da classificação e agregação, que se volta para a escolha das categorias; 2) definição da unidade de registro, que corresponde ao segmento de conteúdo a ser considerado, que pode ser uma frase (desde que exprima um pensamento completo), uma palavra ou uma afirmação acerca de um determinado assunto; e 3) categorização, que é a operação de classificação de elementos pertencentes a um conjunto. ${ }^{13}$ Esse método de análise de dados em pesquisas qualitativas se aplica à análise de textos escritos ou de qualquer comunicação reduzida a um texto ou documento, e tem como objetivo compreender criticamente o sentido das comunicações, seu conteúdo manifesto ou latente e as significações explícitas ou ocultas.

Após as transcrições das entrevistas, a unidade de registro (UR) foi utilizada como estratégia de organização dos dados. Adotou-se a técnica de colorimetria para agrupar as UR afins, o que permitiu uma visão geral da temática. As entrevistas originaram as seguintes UR: solicitação e encaminhamento do pedido de transfusão; coleta de sangue para realizar a prova cruzada; punção do acesso venoso periférico; aferição dos dados vitais; e conferência das bolsas de sangue. Essas URs, por sua vez, fundamentaram a construção da unidade temática "processo pré-transfusional", que deu origem à seguinte categoria: $O$ processo pré-transfusional na atenção ao recém-nascido e sua interface para o cuidado. Essa categoria formou duas subcategorias, a saber: 1) Contextualizando a prática na indicação transfusional e nos exames de compatibilidade sanguínea; e 2) Os cuidados de enfermagem ao recém-nascido ante o procedimento transfusional.

Ressalta-se que o estudo teve como limitação a apreensão, por parte dos profissionais de saúde, em expor seus pensamentos e ideias, que se sentiram "com medo" de serem penalizados pela instituição, caso afirmassem algo em desacordo com o seu trabalho.

\section{RESULTADOS E DISCUSSÃO}

\section{O processo pré-transfusional na atenção ao recém-nascido e sua interface com o cuidado}

O primeiro cuidado no pré-procedimento transfusional refere-se à confirmação da transfusão por meio da prescrição médica, com a sua indicação. Após a confirmação, o processo pré-transfusional tem início com a solicitação médica e o encaminhamento do pedido de hemocomponentes, seguido de coleta de sangue para prova cruzada, obtenção do acesso venoso periférico, aferição dos dados vitais e conferência da bolsa de sangue. O período da etapa pré-transfusional constitui-se no mais crítico durante todo o processo transfusional, considerando que mesmo uma "pequena falha" na identificação do formulário de solicitação de hemocomponentes, poderá comprometer todo o processo. ${ }^{9}$

\section{Contextualizando a prática na indicação transfusional e nos exames de compatibilidade sanguinea}

O estudo permitiu identificar a solicitação do sangue e o encaminhamento do pedido, como os primeiros passos diante da necessidade de transfusão sanguínea para o recém-nascido, mas a maioria dos entrevistados não relatou a conferência desse pedido, como descrito a seguir:

[...] acontece assim, primeiro tem o pedido do sangue, que o médico faz. Nós encaminhamos esse pedido com a etiqueta do paciente. E o responsável pelo sangue e agente administra [...] (PS11).

[...] o médico solicita o sangue e encaminha o pedido para o laboratório. O laboratório traz esse sangue pra gente. Aí administra o sangue [...] (PS25).

A decisão de transfundir o RN é do médico, e ele deverá fazer as anotações no respectivo prontuário e preencher a requisição de hemocomponentes, mencionando: dados do receptor, tipo de hemocomponente solicitado, quantidade solicitada, o motivo da indicação, como também se o hemocomponente deve apresentar algum procedimento especial como 
a desleucocitação e irradiação, que são indicados para RN; se o paciente é politransfundido ou se já apresentou alguma reação transfusional,;,11 modalidade da transfusão, se a mesma será programada, de rotina, de urgência ou emergência; data da requisição, nome, assinatura e número de inscrição no Conselho Regional de Medicina do médico solicitante, e também os antecedentes transfusionais e gestacionais e as reações à transfusão. ${ }^{5,9}$ Esse é o primeiro passo diante da necessidade do processo transfusional, mas os participantes não apontaram para a "checagem" do pedido, que é um aspecto a ser observado com rigor.

Nesse sentido, a conferência do pedido de solicitação da transfusão sanguínea é um importante passo perante o processo da terapia transfusional, para a segurança do RN, como também para a qualidade da assistência ofertada. O enfermeiro, enquanto líder da equipe de enfermagem, é o profissional que detém o conhecimento científico dos processos transfusionais e das reações que podem surgir decorrentes de um erro perante a checagem da solicitação da hemotransfusão. Portanto, torna-se essencial a sua competência perante a conferência desse processo em prol do cuidado do RN.

Ressalta-se essa importância visto que uma transfusão de sangue inadequada pode gerar danos ao RN como, por exemplo, desencadear uma reação transfusional que poderia ter sido evitada. Apenas um participante referiu-se à necessidade de conferir esse pedido, como relatado a seguir:

[...] quando o paciente vai ser transfundido, o enfermeiro deve verificar se a solicitação médica está devidamente preenchida, e caso não esteja, deve devolver e cobrar do médico. E outra coisa é que devemos identificar essa solicitação com a etiqueta de identificação do paciente, para não ter troca de nome [...] (PS17).

Um aspecto que merece destaque é que uma requisição incompleta, inadequada ou ilegível deve ser avaliada pelo enfermeiro, ${ }^{14}$ até porque para que ocorra a transfusão, ele precisa conferir esse pedido de sangue, que deve ser preenchido corretamente, já que se constitui em via documental legal e justifica a necessidade desse procedimento. ${ }^{15}$ Assim, embora o profissional médico seja o responsável pelo preenchimento da requisição, é o enfermeiro quem a encaminha para as providências cabíveis após a conferência dos dados, o que constitui uma dupla checagem dos dados do paciente, aumentando assim a segurança do ato transfusional. ${ }^{5,15}$

Outra questão importante é verificar a religião dos representantes legais do $\mathrm{RN}^{11}$ porque algumas religiões, como no caso das Testemunhas de Jeová, proíbem a prática transfusional. No entanto, nenhum profissional entrevistado citou a importância de observar a questão religiosa. A não observação desse aspecto pode levar ao preparo do sangue, e quando o material chega para ser infundido no RN, os representantes legais não autorizam o procedimento, o que pode resultar em uma má gestão dos recursos.

Após enviar a solicitação dos hemocomponentes, o médico deverá solicitar a amostra de sangue para os testes de compatibilidade sanguínea. É importante que o enfermeiro tenha essa atenção, já que esse teste de compatibilidade, de acordo com a literatura, contém informações importantes para uma transfusão segura, ${ }^{16}$ uma vez que as complicações durante uma transfusão sanguínea são as reações hemolíticas transfusionais, que podem ser fatais, sendo essa a principal causa de morte imediata relacionada à transfusão sanguínea. ${ }^{12}$ Alguns entrevistados citaram a coleta da prova cruzada, como descrito a seguir:

[...] quando o médico entrega o pedido do sangue, a gente colhe o sangue do bebê e identifica com a etiqueta do paciente o tubo da coleta [...] (PS10).

[...] é feita a solicitação dos hemocomponentes, depois que o médico faz a solicitação do sangue. Ele tem que pedir o sangue para a prova cruzada para poder identificar a compatibilidade sanguínea com a bolsa de sangue que está disponível [...] (PS30).

A prova de compatibilidade é um procedimento importante para aumentar a segurança das transfusões sanguíneas, ${ }^{5,9}$ sendo essencial que os enfermeiros atentem para a coleta da prova cruzada, pois toda transfusão deve ser feita com sangue que seja compatível. Outra questão importante é que as amostras devem ser rotuladas no momento da coleta com o nome completo do receptor, o número de identificação ou localização no serviço, a data da coleta e a identificação da pessoa que realizou a coleta da amostra, ${ }^{17}$ pois a cada seis transfusões incompatíveis, uma ocorre devido à troca de amostra do receptor. ${ }^{11}$ Merece destaque o fato de que nenhum enfermeiro citou a identificação, no frasco de sangue, de quem realizou a coleta, conforme exigido pela Resolução da Diretoria Colegiada (RDC) n. 34, de 11 de junho de 2014. ${ }^{3}$ Isso mostra que pode haver falhas em relação à identificação dos frasco, sugerindo desrespeito ao que a legislação recomenda.

Nesse primeiro momento da transfusão, de acordo com os participantes, foi demonstrado que os enfermeiros seguem algumas recomendações da legislação, mas falta atenção em relação a alguns cuidados importantes do processo transfusional. Eles mostram que reconhecem a solicitação, o encaminha- 
mento do pedido de sangue e a coleta de sangue para realizar a prova cruzada, mas pode-se perceber que há pontos falhos em relação à assistência: avaliar a religião, conferir o pedido de sangue e avaliar se as informações que constam do pedido estão condizentes com os dados do recém-nascido; identificar as amostras de tubo de sangue quando se realiza a coleta para prova cruzada, que é uma exigência das legislações ou mesmo das ações de enfermagem diante de uma transfusão de extrema urgência. Esses fatos podem comprometer a segurança do ato e contribuir para erro ao administrar a transfusão no RN que pode promover reações hemolíticas transfusionais fatais, sendo essa a principal causa de morte imediata relacionada à transfusão sanguínea. ${ }^{9}$

Além desses primeiros cuidados que devem ser realizados no ato transfusional, há outros pertinentes à enfermagem que são essenciais nesse primeiro momento, como a importância de se ter um acesso venoso periférico, a aferição dos dados vitais antes de iniciar a infusão e a conferência da bolsa de sangue, aspectos que serão discutidos a seguir.

\section{Os cuidados de enfermagem ao recém-nascido ante o procedimento transfusional}

Os enfermeiros mostraram que atentam para a importância do acesso venoso periférico (AVP), em especial antes da entrega do sangue na unidade. Além disso, avaliam se o AVP está pérvio, o que demonstra um cuidado satisfatório em relação a esse assunto, como está descrito a seguir:

[...] se o recém-nascido não tiver com o acesso periférico, eu peço para o profissional que está no leito para providenciar o acesso [...] (PS20).

[...] a equipe de enfermagem é responsável pela manutenção do acesso venoso periférico. Se o recémnascido não estiver com o acesso, o técnico já punciona. E eu sempre punciono o acesso antes do sangue chegar na unidade. O hemocomponente deve ser infundido em AVP, exclusivamente [...] (PS23).

[...] primeiro o enfermeiro avalia se o recém-nascido tem condição, eu digo se ele está estável para receber o sangue. Se ele estiver em condições, aí eu verifico se o recém-nascido já tem AVP. Se ele não tiver acesso, já punciona antes do sangue chegar na unidade [...] (PS30).

É importante que se tenha o AVP antes do sangue chegar na unidade, para evitar atraso no início da transfusão e causar danos e/ou contaminação das células sanguíneas devido a um tempo maior de exposição, visto que os componentes eritrocitários não devem permanecer à temperatura ambiente por mais de 30 minutos. ${ }^{18}$ Desse modo, se este tempo for atingido, o componente deve ser recolocado, imediatamente, em temperatura adequada de armazenamento. Por isso, é importante que se tenha o AVP antes da entrega do sangue, como apontado pelos enfermeiros, por se tratar de uma prática que promove a segurança do processo, inibindo a contaminação, além de promover a melhor gestão dos recursos da unidade transfusional.

Além disso, a enfermagem deverá obter um AVP, de preferência calibroso, pois além de garantir o fluxo adequado, previne a hemólise. ${ }^{19}$ Vale ressaltar que a alta pressão de fluxo através da agulha ou cateter com pequeno lúmen, pode causar a hemólise dos eritrócitos. ${ }^{20} \mathrm{O}$ AVP deve ser selecionado em local com integridade cutânea, livre de lesões e/ ou hematomas, evitando locais muito próximos às articulações (principalmente quando necessário manter a venopunção para a transfusão), considerando os pacientes com difícil acesso. ${ }^{20} \mathrm{~A}$ equipe de saúde e, principalmente, os profissionais de enfermagem, devem estar atentos, observando periodicamente a venopunção, tendo em mente que o tempo aumentado de exposição da bolsa é um fator de risco para o crescimento bacteriano. ${ }^{21}$ Se houver necessidade de um tempo maior para iniciar a infusão, o hemocomponente deverá ser devolvido ao laboratório para condições adequadas de armazenamento. ${ }^{20}$

Outro ponto importante em relação aos medicamentos que estão sendo infundidos no $\mathrm{RN}^{5}$ é que antes de instalar o hemocomponente, deve-se verificar na prescrição médica quais os medicamentos que serão administrados, pois é preciso ter cuidado com essas soluções e medicações. ${ }^{22}$ Os enfermeiros apontaram a importância de não infundir o sangue junto com outros medicamentos, porque o AVP deve ser exclusivo para a transfusão de sangue, conforme a legislação recomenda e como está descrito nos depoimentos a seguir:

[...] não se deve administrar o sangue junto com antibióticoterapia porque se o paciente tiver alguma reação, eu sei que vai ser do sangue. E a dieta administra normalmente [...] (PS12)

[...] as medicações não devem ser infundidas durante a transfusão, se o médico pedir algum medicamento, eu paro a transfusão, faço a medicação e depois retorno à transfusão [...] (PS17).

[...] durante a transfusão de sangue, eu sempre oriento a equipe a não infundir antibióticos junto com a transfusão [...] (PS23)

Se houver necessidade da administração de medicamentos, o enfermeiro deve interromper a infusão e lavar o AVP com solução fisiológica a $0.9 \%$, antes de administrá-los, ${ }^{23}$ demonstrando que 
tem conhecimento acerca desses cuidados. O ideal é que quando o RN for transfundido, não seja administrada nenhuma medicação no momento da infusão, para não mascarar os sintomas, caso ele tenha alguma reação transfusional, já que os efeitos colaterais dos medicamentos são similares aos sintomas de reações transfusionais. ${ }^{5,9}$

Assim, toda transfusão deve ser acompanhada pelo enfermeiro, responsável por realizar a verificação dos sinais vitais antes de iniciá-la, para fins de comparação caso o RN desenvolva uma reação transfusional, apesar de não serem comuns variações bruscas nos seus sinais vitais durante a transfusão. ${ }^{24} \mathrm{~A}$ legislação do Ministério da Saúde destaca, em relação a essa temática, que o RN deve ter os seus sinais vitais (temperatura, frequência cardíaca, frequência respiratória, pressão arterial) analisados e registrados antes do início da transfusão, ${ }^{5}$ estando os profissionais de acordo com o que a legislação recomenda:

[...] quando a bolsa de sangue está pronta, o laboratório liga e a gente olha a temperatura sempre, antes de o sangue subir pra unidade. Olha também a pressão arterial, e frequência cardiaca e a saturação [...] (PS2).

[...] eu peço para o técnico olhar a temperatura antes da chegada da bolsa. [...] pressão arterial, frequência cardíaca e frequência respiratória [...] (PS14).

[...] sempre antes de começar a transfusão eu avalio os sinais vitais, como a temperatura, frequência respiratória, frequência cardíaca e pressão arterial. Se tem monitor disponível, deixo essa criança monitorada [...] (PS21).

Essa avaliação prévia dos sinais vitais tem uma importante função no monitoramento do $\mathrm{RN}$ e, consequentemente, na detecção precoce de alteração do seu estado clínico, ${ }^{25}$ o que evidencia que os enfermeiros entrevistados têm conhecimento quanto aos cuidados de monitoração inicial dos RN. É de suma importância a avaliação prévia dos sinais vitais, pois este segue como parâmetro no acompanhamento transfusional, caso o RN apresente algum tipo de reação comprometendo, assim, a qualidade da assistência hemoterápica.

Não existe contraindicação absoluta à transfusão em pacientes com febre. ${ }^{4}$ Porém, é importante controlar a febre antes da transfusão, porque o surgimento de febre pode ser um sinal de hemólise ou de outro tipo de reação transfusional. ${ }^{4}$

Se houver alterações nos sinais vitais, deve-se adotar as medidas prescritas e aguardar a normalização para iniciar a transfusão. Após o controle, deve-se avaliar os sinais vitais de hora em hora. ${ }^{26} \mathrm{O}$ $\mathrm{RN}$ deve ser mantido com oximetria de pulso, pois o mesmo pode ser de grande valia, devido a ajuda em reduzir a necessidade de emergências, seja por antecipar os eventos adversos, seja por permitir a detecção precoce de alterações, tanto respiratórias, quanto cardíacas. ${ }^{27}$ Esse monitoramento dos dados vitais tem sido, durante décadas, uma característica padrão no acompanhamento da transfusão. ${ }^{25}$

Outro ponto observado nos depoimentos foi a ausência de relatos acerca do equipo próprio para o procedimento em questão, um item relevante para a atuação do enfermeiro uma vez que o equipo de sangue contém filtro para reter coágulos, impedindo a sua passagem para a corrente sanguínea do paciente, o que pode causar embolia e até mesmo óbito. ${ }^{9}$ Todavia, como a sua utilização não foi apontada pelo enfermeiros, e sequer mencionada, pode-se inferir o descumprimento de um cuidado essencial ao procedimento transfusional.

Um dos maiores problemas relacionados à transfusão de sangue é o erro por incompatibilidade do sistema ABO. Nesse contexto, torna-se importante realizar a checagem da bolsa de sangue. ${ }^{11}$ A conferência dos dados contidos no rótulo da bolsa de sangue e dos dados do prontuário dos RNs, além da identificação positiva do receptor, devem ser obrigatoriamente realizadas antes da instalação de uma transfusão, no sentido de prevenir, entre outros riscos, a sua instalação indevida. ${ }^{1,5}$ De acordo com a discussão em relação à conferência da bolsa de sangue, a RDC 34, de 11 de junho de $2014,{ }^{3}$ descreve os itens que devem constar no rótulo da bolsa de sangue, os quais devem ser checados pelo enfermeiro antes do início de uma transfusão. Desse modo, cabe ao enfermeiro comparar o cartão de transfusão com o prontuário do $\mathrm{RN}$, em especial quanto à identificação completa do mesmo, garantindo que o hemocomponente se destina àquele $\mathrm{RN},{ }^{25}$ confirmando o hemoterápico certo para o cliente certo. ${ }^{5,9}$ Além disso, essa etiqueta contém informações de identificação do $\mathrm{RN}$, bem como dados do produto sanguíneo.

Conforme previsto na legislação, os enfermeiros entrevistados relataram a conferência da bolsa de sangue, apesar de não estarem cumprindo as suas diretrizes perante a legislação, que aponta a necessidade de serem conferidos rigorosamente: nome completo do receptor e identificação numérica do receptor, grupo $\mathrm{ABO}$ e tipo $\mathrm{RhD}$ do receptor; grupo $\mathrm{ABO}$ e tipo $\mathrm{RhD}$ do hemocomponente a ser transfundido; conclusão da prova de compatibilidade; data do envio do hemocomponente; e nome do responsável pela realização dos testes pré-transfusionais e pela liberação. Destaca-se que os profissionais entrevistados referiram-se apenas 
à identificação do receptor, grupo $\mathrm{ABO}$ e fator $\mathrm{RH}$ do receptor, teste de compatibilidade sanguínea e identificação numérica, os quais são exigidos pela legislação, como descrito em seus depoimentos:

[...] quando a gente recebe a bolsa de concentrado de hemácias/plaqueta/plasma, tem que verificar o nome do recém-nascido, tipo sanguíneo do doador e do receptor e se foi realizado teste de compatibilidade, olhar também o número da bolsa e o volume prescrito e recebido [...] (PS17).

[...] eu verifico se a bolsa está com o nome completo do recém-nascido, se é o paciente certo, volume certo, material correto. Só depois dessa conferência é que eu ligo o sangue na criança [...] (PS18).

[...] quando o sangue chega, eu olho o nome do paciente, o leito, a prescrição, o volume, a compatibilidade sanguinea, olho de acordo com essa ficha que fica na bolsa, e também confiro essa ficha com a bolsa de sangue. Aí confiro a ficha e assino o caderno de entrega de hemocomponente [...] (PS25).

Esse cuidado, associado à conferência dos dados do receptor com os da bolsa de hemoterápico, contribui significativamente para prevenir reações ocasionadas por incompatibilidade. Assim, os enfermeiros têm o conhecimento que essa checagem deve ser realizada antes de iniciar a transfusão de sangue, embora nem sempre sigam todos os itens de conferência, o que precisa ser corrigido em termos assistenciais, considerando que a finalidade da correta identificação do RN é reduzir a ocorrência de incidentes. Logo, o processo de identificação deve ser realizado integral e corretamente para assegurar que o cuidado seja prestado à pessoa para a qual se destina. ${ }^{11}$

Além disso, essa etiqueta deve manter-se afixada na bolsa de sangue, de modo que nela permaneça até o término do procedimento, não obstruindo as informações originais da bolsa. ${ }^{17}$ Apenas um entrevistado mencionou a necessidade de manter a etiqueta afixada na bolsa de sangue, como descrito no depoimento a seguir:

[...] o laboratório sobe com o sangue, o enfermeiro recebe, confere a bolsa, entrega para o profissional do leito, o mesmo confere o sangue. Mantém a etiqueta do sangue na bolsa. Grampeia a etiqueta na prescrição [...] (PS13).

Essa conferência se constitui no momento "ouro" de uma transfusão, pois nesse cartão estão as informações do RN, os testes de compatibilidade, além dos dados de identificação, cabendo ao enfermeiro conferir se esse sangue é compatível ou não com o do RN, com o propósito de prevenir um erro, ou troca de RN antes do início da infusão, e até mesmo a ocorrência de hemólise por incompatibilidade ABO.$^{5,9}$ Esse processo é essencial para a segurança do $\mathrm{RN}$, e cabe ao enfermeiro seguir essa etapa, e promover o cuidado ao $\mathrm{RN}$, conforme determina a legislação do MS.

Por isso, uma vez identificada qualquer discrepância, o processo de instalação deve ser interrompido e a transfusão não pode ser iniciada. ${ }^{19}$ Diante de qualquer anormalidade encontrada durante os procedimentos de inspeção e de conferência da bolsa de hemocomponente, a transfusão não deve ser realizada até que o problema seja esclarecido e resolvido. ${ }^{28}$

Pelos relatos obtidos, os enfermeiros demonstraram ter conhecimento de que a bolsa de sangue deve ser conferida antes da instalação do hemocomponente e o acesso venoso periférico, puncionado ou mesmo avaliado antes do início da transfusão ou mesmo antes da bolsa de sangue chegar à unidade. Também referiram preocupação em relação a interromper a transfusão e em não administrar antibióticos no momento em que esse procedimento estivesse sendo realizado. E embora sabendo que os dados vitais devem ser aferidos e avaliados antes do início da transfusão, foram constatados alguns pontos que ainda são falhos na assistência, como a não conferência de todos os dados contidos no rótulo da bolsa de sangue. Como o profissional que administrará o hemocomponente é a última barreira para a detecção de erros antes da transfusão, é imprescindível que todos os dados sejam conferidos. ${ }^{15}$ Caso os dados vitais estejam dentro dos limites de normalidade e os dados da bolsa de sangue estejam corretos, o próximo passo é o momento inicial da transfusão sanguínea.

Frente à demanda das transfusões de sangue no âmbito hospitalar na UTIN e à atuação do enfermeiro, a assistência prestada ao paciente durante todo ato transfusional, fica sob sua responsabilidade. ${ }^{15} \mathrm{O}$ enfermeiro possui como função executar e acompanhar as atividades realizadas pelos técnicos de enfermagem, principalmente acompanhar a transfusão de sangue nos primeiros minutos. ${ }^{29}$ É dele a responsabilidade de assegurar ao cliente uma assistência livre de danos decorrentes de imperícia, negligência ou imprudência. ${ }^{30}$

\section{CONCLUSÃO}

Pode-se observar que os enfermeiros possuem conhecimento do processo da terapia transfusional, mas não cumprem integralmente o que as legislação exige, a exemplo de conferência do pedido de sangue, identificação das amostras de tubo de sangue, conferência de todos os dados contidos no rótulo da bolsa de sangue, itens apontados pelos profissionais, 
mas que não foram executados previamente ao processo transfusional.

Outras questões dizem respeito à verificação da religião dos responsáveis pelos RNs e a assinatura do termo de consentimento pelos mesmos, já que não foram citados por nenhum profissional. Em contrapartida, eles mostraram conhecimento satisfatório em relação à aferição dos dados vitais do paciente no início da transfusão, e os cuidados em relação às possíveis medicações.

Desse modo, confirma-se a necessidade de capacitação e de aprimoramento dos enfermeiros na prática da hemoterapia, visto que o processo pré-transfusional é altamente complexo e que os aspectos não observados rigorosamente, evidenciam que o enfermeiros não detém o conhecimento pleno dessa prática, o que pode resultar em insegurança do processo de cuidado.

Cabe ao enfermeiro, portanto, tomar ciência plena das Resoluções da Agência Nacional de Vigilância Sanitária e do Conselho Federal de Enfermagem, cujos textos podem esclarecer melhor a sua atuação durante o ato transfusional, isto é, o passo a passo dos cuidados de enfermagem antes, durante e após a transfusão sanguínea, o que certamente propiciará o aprimoramento da sua prática assistencial resultando em benefício para todos os envolvidos no processo transfusional na Unidade de Terapia Intensiva Neonatal.

\section{REFERÊNCIAS}

1. Silva KFN, Soares S, Iwamoto HH. A prática transfusional e a formação dos profissionais de saúde. Rev. Bras. Hematol. Hemoter [Internet]. 2009 [cited 2016 Dec 19]; 31(6):. Available from: http://www. scielo.br/pdf/rbhh/v31n6/aop9309.pdf

2. Santos AMN. Indicações de transfusões de hemácias no prematuro. São Paulo: Sociedade Brasileira de Pediatria; 2012.

3. Ministério da Saúde (BR). Agência Nacional de Vigilância Sanitária. RDC n. 34, de 11 de junho de 2014. Dispõe sobre as boas práticas no ciclo do sangue. Brasília: MS; 2014.

4. Duarte ED, Sena RR, Tavares TS. Práticas cuidadoras que favorecem a integralidade do cuidado ao recém-nascido de alto risco: revisão sistemática. Rev Eletr Enferm [Internet]. 2010 [cited 2015 aug 13]; 12(3):. Available from: https://www.fen.ufg.br/ fen_revista/v12/n3/v12n3a18.htm

5. Diniz EMA, Albiero AL, Ceccon MEJ, Vaz FAC. Uso de sangue, hemocomponentes e hemoderivados no recém-nascido. J. Pediatr [Internet]. 2001 [cited 2016 dec 19]; 77(supl.1):. Available from: http:/ / www.jped. com.br/conteudo/01-77-s104/port.pdf
6. Silva PS, Nogueira VO. Hemoterapia: as dificuldades encontradas pelos enfermeiros Cons Scientiae Saúde [Internet]. 2007 [cited $2016 \mathrm{dez}$ 19]; 6(2):. Available from: http://www.redalyc.org/articulo. oa?id=92960216

7. Carmo CMA, Oliveira EM, Pontes KAES, Martins TBB, Cabral TCLG. Procedimentos de enfermagem em UTI neonatal. In: Moreira MEL, Lopes JMA, Carvalho M. O recém-nascido de alto risco: teoria e prática do cuidar. Rio de Janeiro: Fiocruz; 2004.

8. Torezan G, Souza EN. Transfusão de hemoderivados: os enfermeiros estão preparados para o cuidado peritransfusional? Rev. Enferm UFPE online [Internet]. 2010 [cited 2016 Dec 19]; 4(2):. Available from: http:/ / www.revista.ufpe.br/revistaenfermagem/index. $\mathrm{php} /$ revista/article/view/845/pdf_52

9. Barbosa EM, Torres CA, Gubert FA, Pinheiro PNC, Vieira NF. Enfermagem e a prática hemoterápica no Brasil: revisão integrativa. Acta Paul Enferm [Internet]. 2011 [cited 2016 Dec 19]; 24(1):. Available from: http:/ / www.scielo.br/pdf/ape/v24n1/v24n1a20.pdf

10. Melo WS, Bezerra CM, Monteiro FPM, Cardoso VML, Chaves EMC. Newborns characterization transfused in neonatal intensive care unit. Rev Enferm UFPE [Internet]. 2015 [cited 2016 Jan 12]; 9(supl.2):. Available from: http://www.revista.ufpe. $\mathrm{br} /$ revistaenfermagem/index.php/revista/article/ view/6433/pdf_7293

11. Pereima RSMR, Arruda MW, Reibnitz KS, Gelbcke FL. Projeto-escola do centro de hematologia e hemoterapia de Santa Catarina: uma estratégia de política pública. Texto Contexto Enferm [Internet]. 2007 [cited 2016 Jan 12]; 16(3):. Available from: http://www.scielo.br/ pdf/tce/v16n3/a22v16n3.pdf

12. Neto ALS, Barbosa MH. Incidentes transfusionais imediatos: revisão integrativa da literatura. Immediate transfusion incidents: an integrative literature review. Actapaul. Enferm [Internet]. 2012 [cited 2015 Aug 13]; 25(1):. Available from: http://www.scielo.br/pdf/ ape/v25n1/en_v25n1a25.pdf

13. Bardin L. Análise de conteúdo. Lisboa (PT): Edições 70 LDA; 2011.

14. Silva MA, Torres GV, Melo GSM, Costa IKF, Tiburcio MP, Farias TYA. Conhecimento acerca do processo transfusional da equipe de enfermagem da UTI de um hospital universitário. Cienc Cuid Saúde [Internet]. 2009 [cited 2016 Jan 12]; 8(4):. Available from: http:/ / periodicos.uem.br/ojs/index.php/CiencCuidSaude/ article/view/9676/5389

15. Ferreira O, Martinez EZ, Mota CA, Silva AM. Avaliação do conhecimento sobre hemoterapia e segurança transfusional de profissionais de enfermagem. Rev Bras Hematol Hemoter [Internet]. 2007 [cited 2016 Jan 12]; 29(2):. Available from: http:/ / www.scielo.br/pdf/rbhh/v29n2/v29n2a15.pdf

16. Fitzpatrick T. Nursing management of transfusion. In: Popovisk MA, editor. Transfusion reactions. Bethesda: 
AABB press; 1996.

17. Ministério da Saúde (BR). Portaria $n^{\circ} 2.712$, de 12 de novembro de 2013. Brasília: MS; 2013 [cited 2015 Oct 12]. Available from: http://bvsms.saude.gov.br/bvs/ saudelegis/gm/2013/prt2712_12_11_2013.html

18. Ministério da Saúde (BR). Portaria $\mathrm{n}^{\circ} 1.353$, de 13 de junho de 2011. Brasília: MS; 2011 [cited 2015 out 12]. Available from: http://bvsms.saude.gov.br/bvs/ saudelegis/gm/2011/prt1353_13_06_2011.html

19. Martins PRJ, Alves VM, Pereira GA. MoraesSouza H. Frequência de anticorpos irregulares em politransfundidos no Hemocentro Regional de Uberaba-MG, de 1997 a 2005. Rev Bras Hematol Hemoter [Internet]. 2008 [cited 2016 Jan 12]; 30(4):. Available from: http://www.scielo.br/pdf/rbhh/ v30n4/v30n4a08.pdf

20. Silva KFN, Soares S, Iwamoto HH. A prática transfusional e a formação dos profissionais de saúde. Rev Bras Hematol Hemoter [Internet]. 2009 [cited 2016 Jan 12]; 31(6):. Available from: http://www.scielo.br/ pdf/rbhh/v31n6/aop9309.pdf

21. Mattia D, Andrade SR. Cuidados de enfermagem na transfusão de sangue: um instrumento para monitorização o paciente. Texto Contexto Enferm [Internet]. 2016 [cited 2016 Dec 12]; 25(2):. Available from: http://www.scielo.br/pdf/tce/v25n2/ pt_0104-0707-tce-25-02-2600015.pdf

22. Costa JE, Cabral AMF, Simpson CA. O enfermeiro e o contexto em reações transfusionais. Rev Pesq Cuid Fundam [Internet]. 2011 [cited 2015 Aug 13];3(5 esp):.Available from: http://www.seer.unirio.br/index.php/ cuidadofundamental/article/view/2018/pdf_562

23. Ministério da Saúde (BR). RDC n 57 , de 16 de dezembro de 2010. Brasília: MS; 2010 [cited 2015 Oct 12]. Available from: http:/ / bvsms.saude.gov.br/bvs/ saudelegis/anvisa/2010/res0057_16_12_2010.html

24. Schöninger N, Duro CLM. Atuação do enfermeiro em serviço de hemoterapia. Cienc Cuid Saude
[Internet]. 2010 [cited 2015 Oct 12]; 9(2):. Available from: http://www.periodicos.uem.br/ojs/index. $\mathrm{php} /$ CiencCuidSaude/article/view/11239/6082.

25. Souza GF, Nascimento ERP, Lazzari DD, Böes AA, Iung $\mathrm{W}$, Bertoncello KC. Good nursing practices in the intensive care unit: care practices during and after blood transfusion. Rev Min Enferm [Internet]. 2014 [cited 2015 Oct 12]; 18(4):. Available from: http:// www.reme.org.br/artigo/detalhes/974

26. Silva KFN, Barichiello E, Mattia AL, Barbosa MH. Nursing care procedures in response to adverse events to blood donation. Texto Contexto Enferm [Internet]. 2014 [cited 2016 Mar 30]; 23(3):. Available from: http://www.scielo.br/pdf/tce/v23n3/01040707-tce-23-03-00688.pdf

27. Narvey M, Fletcher MA. Avaliação e classificação física. In: MacDonald MG, Seshia MK, Mullett MD. Avery neonatologia fisiopatologia e tratamento do recém-nascido. $6^{\text {a }}$ ed. Rio de Janeiro: Guanabara Koogan; 2007.

28. Santos SP, Tanaka LH, Gusmão A, Abreu RGS, Carneiro IA, Carmagnani MIS. Avaliação dos registros de enfermagem em hemoterapia de um hospital geral. Av Enferm [Internet]. 2013 [cited 2016 Mar 30]; 31(1):. Available from: http://www.scielo.org.co/pdf/ aven/v31n1/v31n1a10.pdf

29. Barbosa HB, Nicola AL. Enfermagem na terapia transfusional e hemovigilância: análise da conformidade de um hospital ensino. Saúde (Santa Maria) [Internet]. 2014 [cited 2016 Mar 30]; 40(2):. Available from: https://periodicos.ufsm.br/ revistasaude/article/view/13074/pdf

30. Freitas BAC, Franceschini SCC. Fatores associados à transfusão de concentrado de hemácias em prematuros de uma unidade de terapia intensiva. Rev Bras Ter Intensiva [Internet]. 2012 [cited 2016 Mar 30]; 24(3):. Available from: http://www.scielo.br/pdf/ rbti/v24n3/v24n3a04.pdf
Correspondência: Diego Pereira Rodrigues

Rua Desembargador Leopoldo Muylaert, 307

24350-450 - Piratininga, Niterói, RJ

E-mail: diego.pereira.rodrigues@gmail.com
Recebido: 14 de abril de 2016

Aprovado: 03 defevereiro de 2017

This is an Open Access article distributed under the terms of the
Creative Commons (CC BY) 